\title{
Study of an Energy Regeneration System with Accumulator for Hydraulic Impulse Testing Equipment
}

\author{
Zaipeng Man* - Fan Ding - Chuan Ding - Shuo Liu \\ Zhejiang University, The State Key Lab of Fluid Power Transmission and Control, China
}

To guarantee the reliability and performance of hydraulic systems, it is of vital importance to do hydraulic impulse testing for hydraulic components. However, the testing time is usually so long that the energy consumption is very large. An energy regeneration system with an accumulator is proposed and used for hydraulic impulse testing equipment. Mathematical analysis and simulations show that the hydraulic impulse testing system with an accumulator can reduce energy consumption by $15 \%$ compared with that of the system without an accumulator in the cycle. Furthermore, the energy efficiency of the hydraulic impulse testing system is increased from 62.82 to $75.71 \%$ by the use of an accumulator. Both simulation results and experimental results show that the control performance of the hydraulic impulse testing equipment with an accumulator is better than that of the equipment without an accumulator, and has a faster response speed and a larger pressure rise rate.

Keywords: hydraulic impulse testing, energy regeneration, hydraulic accumulator, simulation, experiment, energy storage

Highlights
- $\quad$ Proposed energy regeneration system with accumulator.
- $\quad$ Mathergy regeneration system used for hydraulic impulse testing.
- $\quad$ Effects on energy consumption models built for the system.
- $\quad$ Better control performance proved by simulation and experiment results.

\section{INTRODUCTION}

Hydraulic transmission systems are widely used in construction and agricultural machinery owing to their high power density, high compactness, and flexible control [1]. However, with fuel prices increasing and an energy crisis looming, the large energy consumption of hydraulic systems is drawing more and more attention [2]. In order to improve the efficiency of hydraulic transmission systems and reduce energy consumption, many methods have been put forward. It is claimed that an energy-saving hydraulic system should be able to recover energy during deceleration or while a load is lowered [3]. Various energy-saving hydraulic systems have been studied, such as secondary control systems and constant pressure systems [4] to [6]. An energy regeneration system in hydraulic forklift trucks has been studied, concentrating on energy recovery in the main lift system with electric motor and batteries, and resulting in improved energy efficiency but shorter lifetime of components [7]. An energy recovery system with a hydraulic accumulator that could save and restore energy in a crane's hydraulic system has also been studied, and it was found that the potential energy of the crane and load can be saved in the form of hydraulic energy and reutilized [8]. A speed control system of a variable voltage variable frequency hydraulic elevator with a pressure accumulator was studied, and was shown to have higher efficiency compared with a hydraulic elevator without a pressure accumulator [9]. A new hydraulic closed-loop hydrostatic transmission energy-saving system has been proposed, and results indicate that the efficiency can be improved by using a hydraulic accumulator [3]. The energy regeneration systems for hybrid hydraulic excavators have also been studied, and it was found that an estimated $41 \%$ of the total potential energy could be regenerated at the lowering of the boom [10].

On the other hand, it is widely recognized that many hydraulic system accidents and component failures are caused by hydraulic impulse rather than overload [11]. So it is of vital importance to do hydraulic impulse testing for hydraulic components, including hydraulic hoses, fittings, assemblies, and so on. Although energy recovery applications are widely used in industry, few energy recovery systems have been developed for hydraulic impulse testing equipment. According to the relevant standards, impulse testing time may be up to 280 hours, which uses a lot of energy [12] to [15]. So it is of great importance to reduce energy consumption during impulse testing. The SAE proposed a standard for impulse machine equipment and operation, which has become the reference for most of later impulse testing equipment [16]. A new hydraulic intensifier 
has been proposed, which can be used for hydraulic impulse testing [17]. The ramp-output response of hydraulic impulse testing equipment and parameter adjustment for a standard pulse has been studied, and good performance of the system has been achieved [18]. All of these above mentioned systems can achieve the desired pressure curves. However, high energy consumption and energy waste are the main drawbacks.

As the hydraulic accumulator can store and release energy over a short period of time, it is a good choice for energy regeneration in hydraulic impulse testing equipment, since the cycle time of hydraulic impulse testing is generally very short.

In this paper, an energy regeneration system with a hydraulic accumulator is used for hydraulic impulse testing. The energy consumption and system efficiencies of the hydraulic impulse testing equipment with an accumulator are compared with those of hydraulic impulse testing equipment without an accumulator using mathematical analysis and simulations. The results show that the energy regeneration system can reduce energy consumption by $15 \%$ and increase system efficiency from 62.82 to $75.71 \%$. Experiments have been carried out to study the control performance of the energy regeneration system for hydraulic impulse testing equipment with an accumulator, and the results show that a faster response speed and a larger pressure rise rate can be obtained.

\section{SYSTEM DESCRIPTION}

A schematic diagram of the energy regeneration system with hydraulic accumulator for hydraulic impulse testing equipment is shown in Fig. 1. It mainly consists of the pressure source, servo valve, pressureboost cylinder, accumulator, check valve, and test components. The pressure source, including a variable displacement pump, a check valve, a relief valve, and an accumulator, is used to provide hydraulic power for the system. Since some hydraulic components need to be tested under high pressure, a pressureboost cylinder is utilized to achieve a pressure higher than that of the pressure source. The pressure-boost cylinder is designed to work in a differential mode, under the control of the three-way servo valve. The cylinder mainly consists of four chambers, in particular, the control chamber connected to the servo valve, system-pressure-chamber connected to the pressure source, the boost chamber connected to the test components, and the accumulator chamber connected to the accumulator. The test components can be hydraulic hoses, fittings, assemblies and so on. A check valve is used to supplement hydraulic oil for the test components.

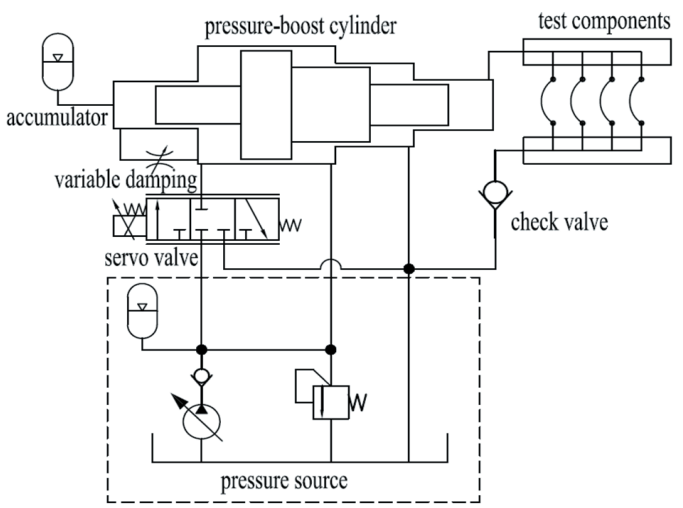

Fig. 1. Energy regeneration system for hydraulic impulse testing equipment

It should be noted that there are two accumulators in Fig. 1. One is connected to the accumulator chamber of the pressure-boost cylinder, the other is connected to the pump in the pressure source. Bladder accumulators are adopted due to their rapid response, long service life, and small dimensions. Both of them are helpful in reducing the energy consumption of the system. However, the accumulator connected to the pump is mainly used for absorbing pulsation of the pressure source, and is not the focus of this paper. Therefore, the accumulator referred to hereafter is the one connected to the accumulator chamber of the pressure-boost cylinder.

For simplicity of analysis, the motion of the piston of the cylinder is divided into two strokes. When a positive signal is provided for the servo valve, the piston of the hydraulic cylinder moves to the right, so the hydraulic oil in the test components is compressed and correspondingly the pressure rises, which is defined as the boost stroke. In contrast, when a negative signal is provided for the servo valve, the piston of the hydraulic cylinder moves to the left, so the hydraulic oil in the test components is released and correspondingly the pressure decreases, which is defined as the return stroke.

The key component of the energy regeneration system is the accumulator attached to the accumulator chamber of the pressure-boost cylinder. A variable damping is designed, in a mechanical structure way, between the accumulator chamber and the control chamber of the cylinder, as shown in Fig. 1. At the end stage of the boost stroke, the variable damping is so small that the accumulator may be considered as directly connected to the control chamber. Hydraulic 
oil can be provided by the pressure source through the servo valve. Then in the return stroke, the variable damping becomes larger. At the end of the return stroke, the damping is so large that the accumulator may be considered as isolated from the control chamber. Correspondingly, the gas in the accumulator is compressed, and the hydraulic energy in the test components and from the pressure source is recovered by the accumulator. In the next boost stroke, the energy stored in the accumulator can be released to help push the piston.

To get better control performance of the output pressure, a feedback control method is adopted, with a pressure sensor detecting the pressure of the boost chamber of the cylinder, and a controller, which are neglected in the schematic diagram for simplicity.

\section{MATHEMATICAL ANALYSIS}

To analyze the advantages of the energy regeneration system with hydraulic accumulator for hydraulic impulse testing equipment, comparisons should be done between hydraulic impulse testing equipment with and without accumulator, especially the energy consumption and system efficiencies. The hydraulic impulse testing system with accumulator is shown in Fig. 1, and the system without accumulator is the same as in Fig. 1, except that the accumulator connected to the cylinder and the corresponding chamber of the cylinder are omitted. For simplicity, as defined in Section 1, the boost stroke and return stroke may be analyzed separately under some conditions.

\subsection{Power of the System without Accumulator}

\subsubsection{Load Power}

In the boost stroke, load power means the power consumption of the test components, and in the return stroke, load power means the output power of the test components. In both cases, load power of the hydraulic impulse testing system without accumulator is given as:

$$
P_{L}=p_{L} q_{L}
$$

where $p_{L}$ is the pressure of the test components, which can be measured with a pressure sensor, and $q_{L}$ is the flow rate at the inlet of the test components, which is given as:

$$
q_{L}=\frac{d V_{L}}{d t}
$$

where $V_{L}$ is the volume of the test components, including the boost chamber of the cylinder connected together. According to the pressure formula of closed volume chambers:

$$
d p_{L}=\frac{E \cdot d V_{L}}{V_{L}}
$$

where $E$ is the equivalent bulk modulus, determined by the bulk modulus of the test components $E_{c}$ and the bulk modulus of the hydraulic oil $E_{o}$, and can be given as:

$$
\frac{1}{E}=\frac{1}{E_{c}}+\frac{1}{E_{o}}
$$

\subsubsection{Power of the Pressure Source}

In the boost stroke, a positive signal is input to the servo valve, and the control chamber of the cylinder is connected to the pressure source through the servo valve. It should be noticed that the system-pressurechamber of the cylinder is always connected to the pressure source. Therefore the pressure-boost cylinder works in a differential mode, and the power of the pressure source is determined by the system pressure $p_{s}$, the difference of the input flow rate into the control chamber $q_{1}$ and the output flow rate from the systempressure-chamber $q_{2}$. For simplicity, it is assumed that the pressure drop of the servo valve is small enough to be omitted. Therefore the power of the pressure source in the boost stroke can be given as:

$$
P_{s B}=p_{s} \cdot\left(q_{1}-q_{2}\right) \text {. }
$$

On the return stroke, a negative signal is input to the servo valve and the control chamber of the cylinder is connected to the tank through the servo valve. The system-pressure-chamber of the cylinder is still connected to the pressure source so the piston of the cylinder moves to the left and the power of the pressure source can be given as:

$$
P_{s R}=p_{s} \cdot q_{2} \text {. }
$$

\subsection{Power of the System with Accumulator}

The calculations of the load power and the pressure source power of the hydraulic impulse testing system with accumulator is the same as that of the system without accumulator, as mentioned in 2.1. The only difference is that a hydraulic accumulator and corresponding variable damping are adopted. 


\subsubsection{Power of the Accumulator}

On the boost stroke, the power of the accumulator means the output power of the accumulator and, on the return stroke, the power of the accumulator means the power stored in the accumulator. In both cases, the power of the accumulator of the hydraulic impulse testing system is given as:

$$
P_{a}=p_{a} \cdot q_{a}
$$

where $p_{a}$ is pressure at the inlet of the accumulator, which can be measured by a pressure sensor, and $q_{a}$ is the flow rate at the inlet of the accumulator. Since the cycle time of the hydraulic impulse testing is very short, the accumulator can be considered to be working in an adiabatic process. And according to the polytropic gas law:

$$
p_{a} V_{a}^{1.4}=p_{0} V_{0}^{1.4}=\text { cons. }
$$

where $V_{a}$ is the gas volume of the accumulator, and $p_{0}$ and $V_{0}$ are the initial pre-charge pressure and initial gas volume of the accumulator, respectively. The flow rate at the inlet of the accumulator is given as:

$$
q_{a}=\frac{d V_{a}}{d t} .
$$

\subsubsection{Variable Damping}

The variable damping between the accumulator chamber and the control chamber of the cylinder is designed by the mechanical clearance, which is determined by the length $l$ of the gap seal. The flow rate through the clearance of the accumulator chamber and the control chamber of the cylinder is given as:

$$
q_{d}=\frac{\pi d \delta^{3}}{12 \mu l} \cdot \Delta p \pm \frac{\pi}{2} \cdot d \delta u,
$$

where $d$ is the piston diameter in the accumulator chamber, which is used for the mechanical gap seal, $\delta, l$ are the clearance and length of the seal, $\mu$ is the dynamic viscosity of the hydraulic oil, and $u$ is the velocity of the piston.

It can be concluded from formula (10) that the damping changes with the gap seal length $l$, which is determined by the location of the piston. When the piston moves to the right end of the cylinder, the seal length $l$ is designed to be small enough so that hydraulic oil can be supplemented for the accumulator chamber. In contrast, when the piston moves to the left end of the cylinder, the seal length $l$ is designed to be long enough so that the accumulator chamber is isolated from the control chamber in a short time. As a result, the gas in the accumulator can be compressed and a higher pressure can be obtained to store energy.

\subsection{Energy Consumption of the System without Accumulator}

\subsubsection{Energy Consumption of the Load}

In both the boost stroke and the return stroke, the energy consumption of the load of the hydraulic impulse testing system without accumulator is given as:

$$
E_{L}=\int p_{L} \cdot q_{L} d t
$$

It should be noted that in the return stroke, Eq. (11) means stands for the energy output of the test components.

\subsubsection{Energy Consumption of the Pressure Source}

In the boost stroke, the energy consumption of the pressure source is given as:

$$
E_{s B}=\int p_{s} \cdot\left(q_{1}-q_{2}\right) d t .
$$

In the return stroke, the energy consumption of the pressure source is given as:

$$
E_{s R}=\int p_{s} \cdot q_{2} d t
$$

\subsection{Energy Consumption of the System with Accumulator}

The calculations of the energy consumption of the load and the pressure source of the hydraulic impulse testing system with accumulator is the same as that of the system without accumulator, as mentioned in 2.3. The only difference is that a hydraulic accumulator is adopted, the energy consumption of which is given as:

$$
E_{a}=\int p_{a} \cdot q_{a} d t
$$

It should be noted that in the return stroke, Eq. (14) means the energy stored in the accumulator, while in the boost stroke, Eq. (14) means the energy released by the accumulator, which works as a power source.

\subsection{Energy Efficiency of the System without Accumulator}

\subsubsection{Boost Stroke}

In the boost stroke, the pressure source is the only energy source for the load, so the energy efficiency 
of the hydraulic impulse testing system without accumulator is given as:

$$
\eta_{W B}=\frac{E_{L}}{E_{s B}}
$$

\subsubsection{Return Stroke}

In the return stroke, both the energy from the test components and from the pressure source turns into heat eventually, so the energy efficiency of the hydraulic impulse testing system without accumulator is 0 .

\subsection{Energy Efficiency of the System with Accumulator}

\subsubsection{Boost Stroke}

In the boost stroke, both the pressure source and the accumulator provide energy for the test components, so the energy efficiency of the hydraulic impulse testing system with accumulator is given as:

$$
\eta_{A B}=\frac{E_{L}}{E_{a}+E_{s B}} .
$$

\subsubsection{Return Stroke}

In the return stroke, besides the energy from the pressure source, the high pressure energy stored in the test components is released and converted to the high pressure energy stored in the accumulator. So the energy efficiency of the hydraulic impulse testing system with accumulator is given as:

$$
\eta_{A B}=\frac{E_{a}}{E_{L}+E_{s R}} .
$$

\subsubsection{Total Efficiency}

Since in the return stroke, no energy is input to the load, the only useful energy into the load is the energy from the pressure source and accumulator in the boost stroke. So the total efficiency of the systems without and with accumulator is given as:

$$
\eta_{T}=\frac{E_{L}}{E_{S B}+E_{s R}},
$$

where $E_{L}$ is the load energy consumption in the boost stroke.

\section{SIMULATION AND CALCULATIONS}

To further compare the energy consumptions and system efficiencies of the hydraulic impulse testing systems with and without accumulator, simulation models are built in AMESim, as shown in Figs. 2 and 3. In the simulation model, the pressure-boost cylinder is built using the hydraulic component design library in the AMESim.

Table 1. Simulation parameters

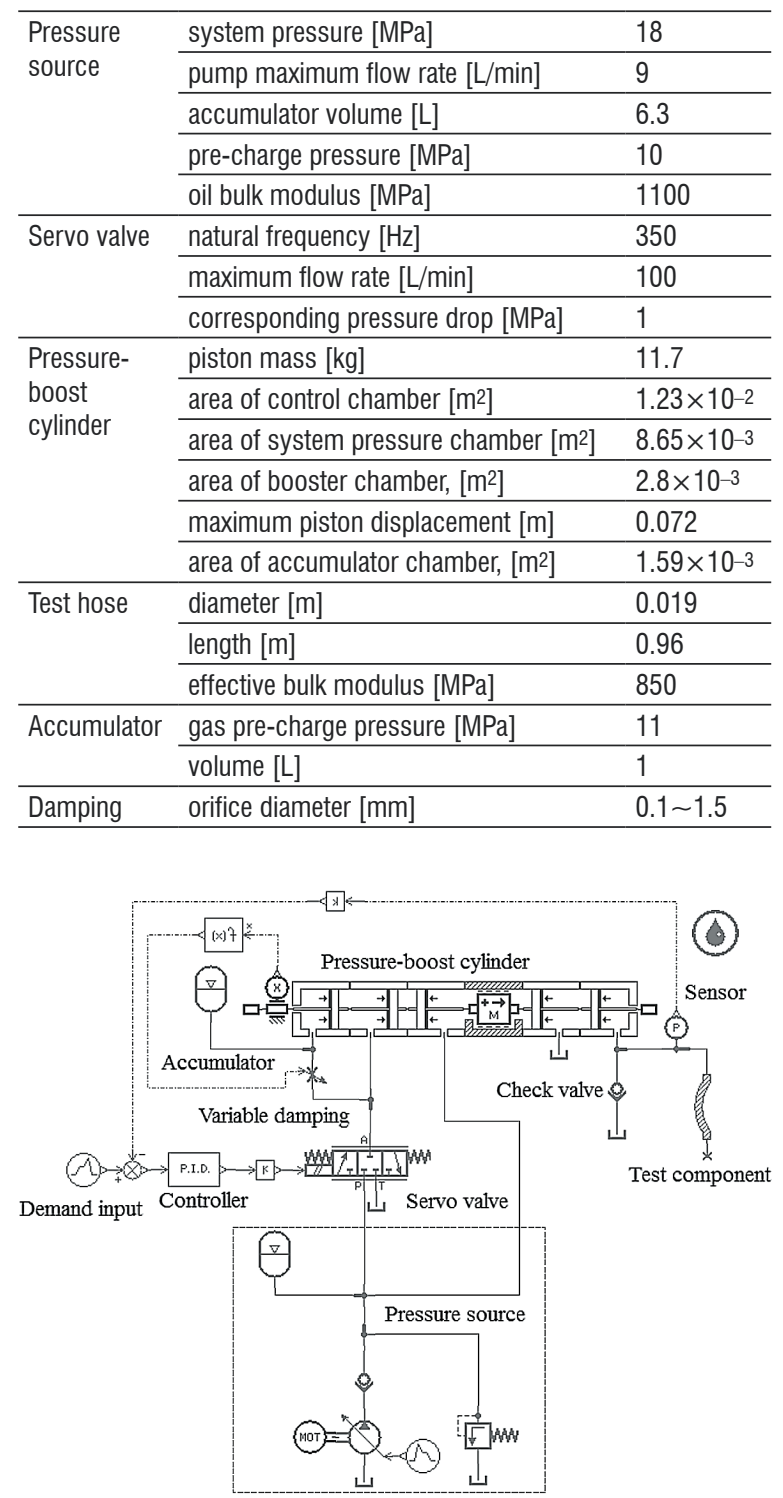

Fig. 2. Simulation model of the system with accumulator

Other hydraulic components such as the pressure source, check valve, pressure sensor, and accumulator are built using the standard hydraulic library. The test component is a hydraulic hose. To compare the 
simulation results of the two systems, the simulation parameters are the same and are shown in Table 1. It should be noted that in Table 1, the parameters of the accumulator and variable damping is only suitable for the energy regeneration system for hydraulic impulse testing equipment with accumulator.

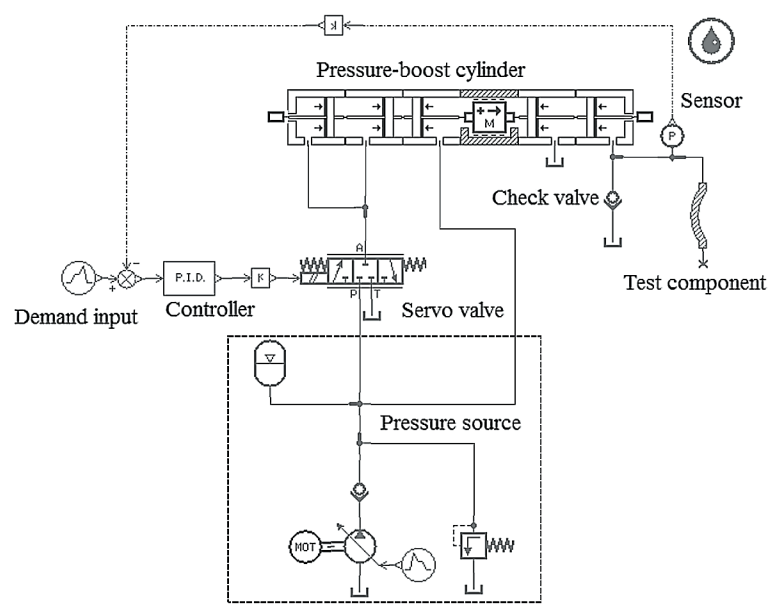

Fig. 3. Simulation model of the system without accumulator

In order to analyze both the boost stroke and return stroke of the systems, a square-wave demand input (or in other words, the desired output pressure), is adopted for the simulation, as shown in Fig. 4.

\subsection{Comparisons of the Power of Systems with and without Accumulator}

\subsubsection{Load Power}

Although the desired output pressures of the hydraulic impulse testing systems with and without accumulator are set to the same values, as shown in Fig. 4, there is still a minor difference in the actual output pressures of the two systems, as shown in Fig. 5. The flow rate at the inlet of the test component of the two systems is shown in Fig. 6. The positive data means that the hydraulic oil flows into the test component, while the negative data means that the hydraulic oil flows out of the test component. It is easy to see that at the initial stage of the boost stroke, the flow rate into the test component of the system with accumulator is larger than that of the system without accumulator, which is a result of the release of energy from the accumulator. Correspondingly, the output pressure of the system with accumulator rises faster than that of the system without accumulator, which can be explained by Eqs. (2) and (3).

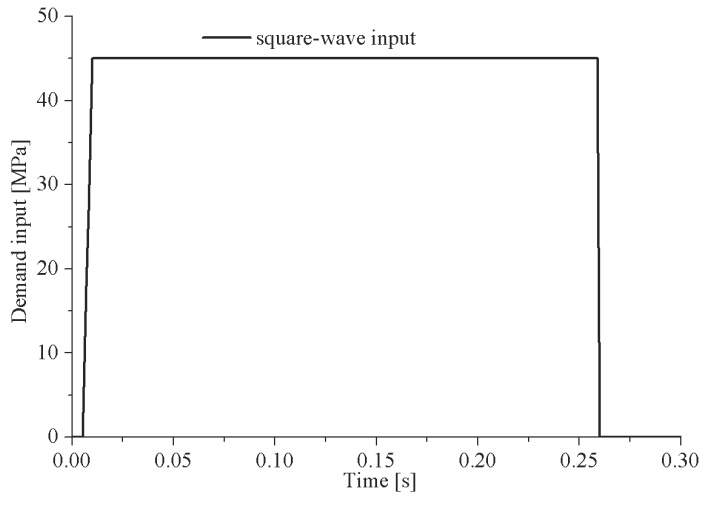

Fig. 4. Square-wave demand input for simulation

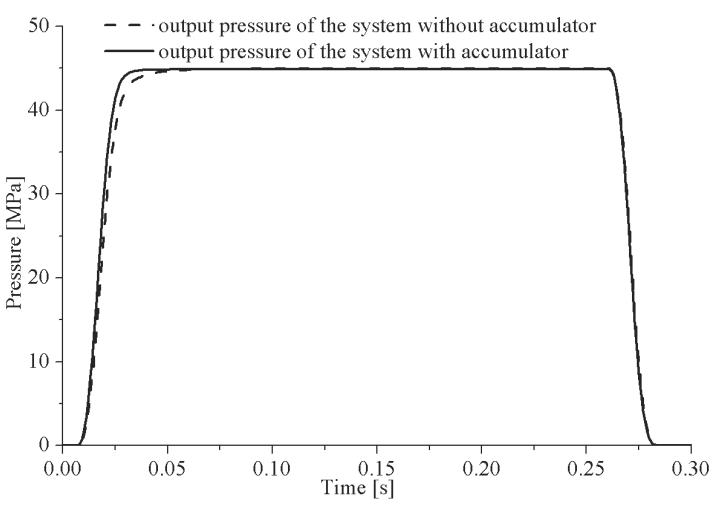

Fig. 5. Output pressure of the system

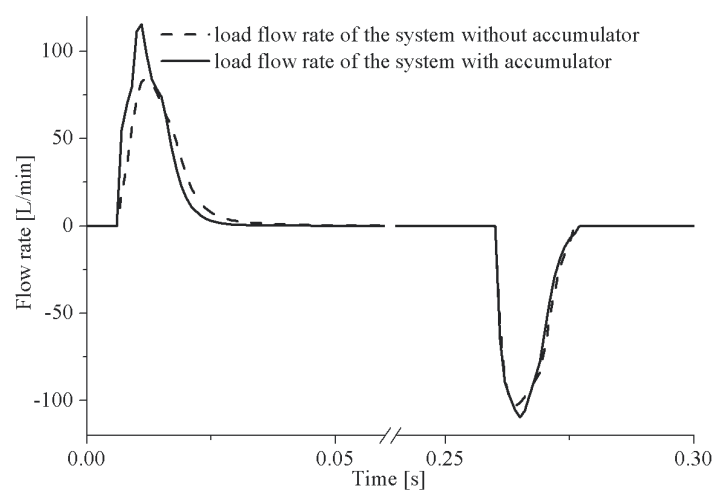

Fig. 6. Load flow rate of the system

According to Eq. (1), the load power of the hydraulic impulse testing systems can be calculated, as shown in Fig. 7. In the boost stroke, hydraulic oil flows into the test component, so the load consumes energy, shown as a positive result. On the other hand, in the return stroke, the test component works as an energy source to push the piston backward, and the load power is shown as a negative result. It should be noted that in the boost stroke, the maximum load power of the system with accumulator appears earlier 
and larger than that of the system without accumulator because of the release of energy from the accumulator. In addition, it cannot be overlooked that in the return stroke, the load power is so large that it would be a huge waste if it were not recovered.

As can be seen from Figs. 6 and 7, in the boost stroke there is a significant difference between the load flow rate and the load power of the system with and without accumulator, while there is only a minor difference in the return stroke. The reason is that in the boost stroke, the pressure rise rate is so large that the flow rate from the pressure source is insufficient, which can be compensated by the accumulator. So, the flow rate supported by the accumulator makes a big difference. In the return stroke, energy released by the load is almost the same for the system with and without accumulator. The only difference is that for the system with accumulator some of the energy is absorbed by the accumulator, while for the system without accumulator all of the energy is wasted. However, the flow rate and power of the load are not affected.

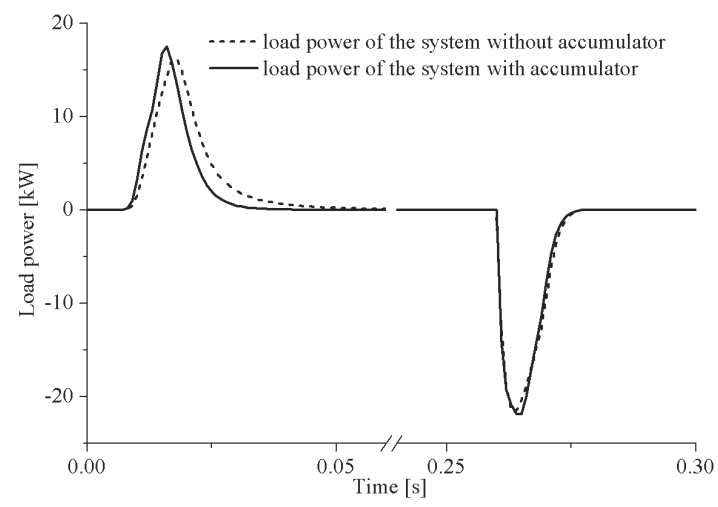

Fig. 7. Load power of the system

\subsubsection{Power of the Pressure Source}

Given that the system pressure is set at a fixed value of $18 \mathrm{MPa}$, the power of the pressure source is mainly determined by the system flow rate, which is shown in Fig. 8. In the boost stroke, the pressure-boost cylinder works in a differential mode, so the system flow rate is calculated by the difference of the input flow rate into the control chamber of the cylinder and the output flow rate from the system-pressure-chamber of the cylinder. While in the return stroke, the system flow rate is just the flow rate into the systempressure-chamber of the cylinder. For convenience of comparison, both the system flow rate in the boost stroke and the system flow rate in the return stroke are shown in the same figure. It should be noted that the instantaneous large flow rate of the system is provided by the accumulator in the pressure source rather than the pump.

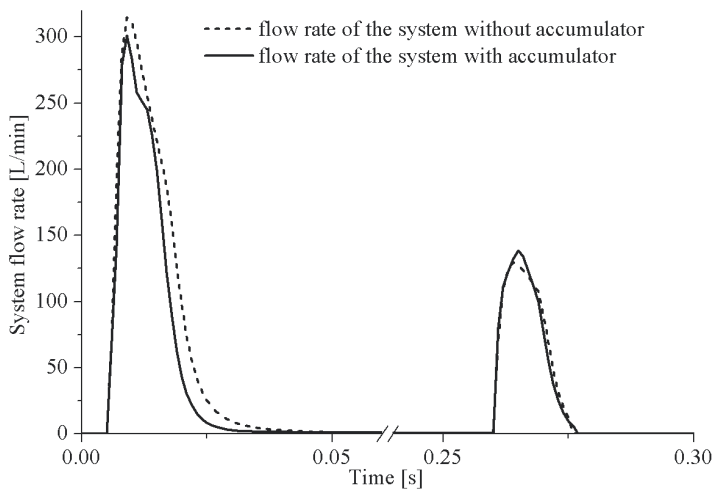

Fig. 8. Flow rate of the system pressure source

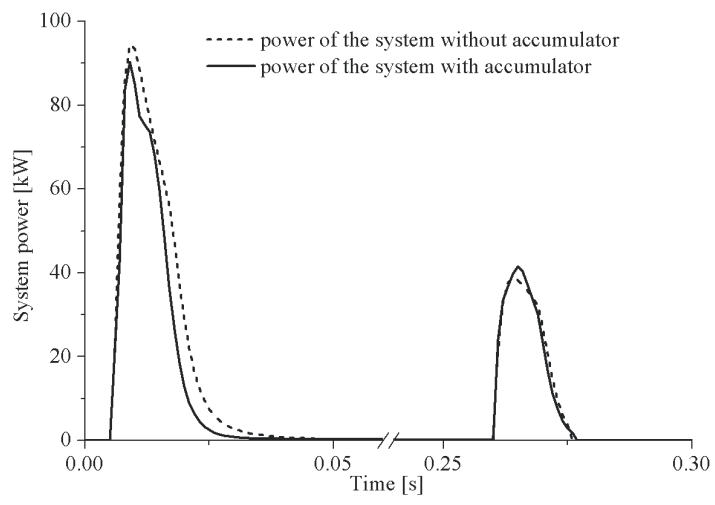

Fig. 9. Power of the system pressure source

According to Eqs. (5) and (6), the power of the systems can be calculated, as shown in Fig. 9. As can be seen from the figure, the maximum pressure source power of the system without accumulator is significantly greater than that of the system with accumulator.

\subsubsection{Power of the Accumulator}

For the hydraulic impulse testing system with accumulator, the pressure and flow rate at the inlet of the accumulator are shown in Fig. 10. For the flow rate, the positive data means that the hydraulic oil flows out of the accumulator, while the negative data means that the hydraulic oil flows into the accumulator. According to Eq. (7), the power of the accumulator of the hydraulic impulse testing system with accumulator can be calculated, as shown in Fig. 11. As with the flow rate, the positive data means that 
the accumulator works as an energy source, while the negative data means that the accumulator absorbs energy.

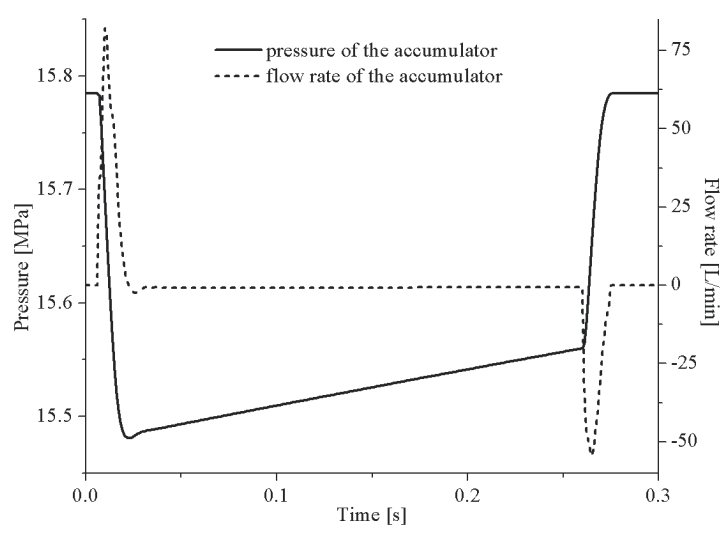

Fig. 10. Pressure and flow rate of accumulator

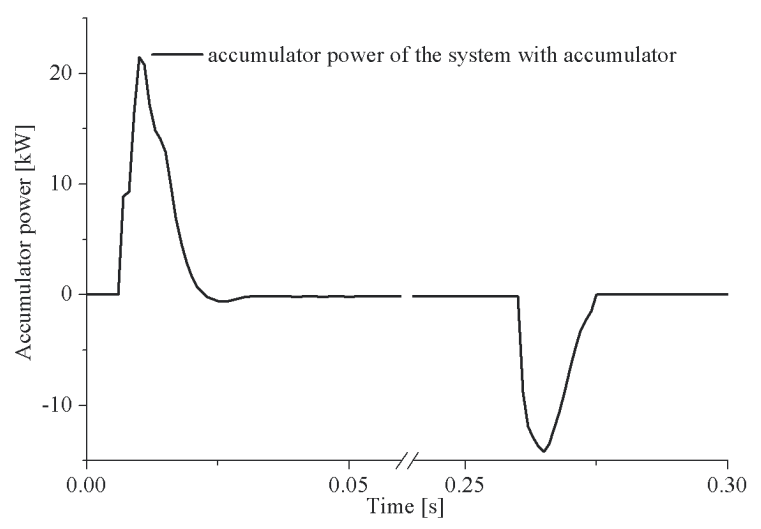

Fig. 11. Power of the accumulator

\subsection{Comparison of Energy Consumption of Systems with and without Accumulator}

For the hydraulic impulse testing system without accumulator, the energy consumption can be calculated by Eqs. (11) to (13); the calculated results are shown in Table 2. In the return stroke, the energy stored in the test component is released, so the energy consumption of the load is negative, which means that it is wasted. In both the boost stroke and the return stroke, the pressure source is constantly working, so the energy consumption remains positive.

For the hydraulic impulse testing system with accumulator, the energy consumption can be calculated by Eqs. (11) to (14); the calculated results are shown in Table 3. As in the system without accumulator, the negative energy consumption of the load in the return stroke means the energy released by the load. In addition, the negative energy released by the accumulator in the return stroke means energy stored in the accumulator.

Table 2. Energy consumption of the system without accumulator

\begin{tabular}{lccc}
\hline Motion direction & Time [ms] & Pressure source [J] & Load [J] \\
\hline Boost stroke & 27 & 1078 & 877 \\
\hline Return stroke & 15 & 318 & -859 \\
\hline \multicolumn{2}{l}{ Total energy consumption } & 1396 & - \\
\hline
\end{tabular}

Using the data in Table 3, we can determine that the energy recovery rate of the accumulator in the return stroke is $(197 / 875) \times 100=22.5 \%$, and the energy reuse rate of the accumulator in the boost stroke is $(193 / 197) \times 100=98 \%$.

By comparing the data in Table 2 and Table 3 , it can be concluded that the system with accumulator can reduce energy consumption by $((1396-1186) / 1396) \times 100=15 \%$ per cycle.

Table 3. Energy consumption of the system with accumulator

\begin{tabular}{lcccc}
\hline $\begin{array}{l}\text { Motion } \\
\text { direction }\end{array}$ & Time $[\mathrm{ms}]$ & $\begin{array}{c}\text { Pressure } \\
\text { source }[\mathrm{J}]\end{array}$ & $\begin{array}{c}\text { Accumulator } \\
{[\mathrm{J}]}\end{array}$ & Load [J] \\
\hline Boost stroke & 22 & 861 & 193 & 898 \\
\hline Return stroke & 16 & 325 & -197 & -875 \\
\hline Total energy consumption & 1186 & - & - \\
\hline
\end{tabular}

\subsection{Comparisons of Energy Efficiency of Systems with and without Accumulator}

In the boost stroke, the efficiency of the hydraulic impulse testing system without accumulator can be calculated by Eq. (15) and the data in Table 2. In the return stroke, the efficiency of the hydraulic impulse testing system without accumulator is 0 , as analyzed in 2.5.2.

In the boost stroke, the efficiency of the hydraulic impulse testing system with accumulator can be calculated by Eq. (16) and the data in Table 3. In the return stroke, the efficiency of the hydraulic impulse testing system with accumulator can be calculated by Eq. (17) and the data in Table 3.

Comparisons of the energy efficiency are shown in Table 4. The total efficiency of the system is calculated by the energy consumption of the load in the boost stroke divided by the total energy consumption of the pressure source. It is apparent that the efficiency of the system with accumulator is higher than that of the system without accumulator. The reason is that in the return stroke, the system with accumulator can recover energy from the load and then release the recovered energy in the next boost 
stroke, while for the system without accumulator, the energy stored in the load is totally wasted in the return stroke and turns into heat.

Table 4. Comparisons of the energy efficiency of the hydraulic impulse testing system

\begin{tabular}{lcc}
\hline Motion direction & $\begin{array}{c}\text { System without } \\
\text { accumulator [\%] }\end{array}$ & $\begin{array}{c}\text { System with } \\
\text { accumulator [\%] }\end{array}$ \\
\hline Boost stroke & 80.68 & 85.2 \\
\hline Return stroke & 0 & 16.4 \\
\hline Total efficiency & 62.82 & 75.71 \\
\hline
\end{tabular}

\section{CONTROL PERFORMANCE}

To study the control performance of the energy regeneration system with accumulator for hydraulic impulse testing equipment, experiments were carried out on a prototype. The performance of the hydraulic impulse testing equipment is compared with that of the hydraulic impulse testing equipment without accumulator. To compare the experimental results with the simulation results, the parameters of the prototype are set the same with the simulation models, which are shown in Table 1.

\subsection{Step-Input Response}

The step-input response of the hydraulic impulse testing system with and without accumulator is studied. Both the simulations and experiments were carried out, the results of which are shown in Figs. 12 and 13. The key data of for the results is shown in Tables 5 and 6 . As can be seen from the results, both systems can achieve the goal with a minor steady state error. However, the system with accumulator can achieve the goal with at a faster speed than the system without accumulator, which is the result of the energy regeneration by the accumulator.

It should be noted that there are some differences between the simulation and the experimental results. The response time lag of the experimental results is more apparent compared with the simulation results, the reason for this is that the damping forces of the seals and the piston in the simulation model are neglected and some parameters such as the bulk modulus of the hydraulic oil may be slightly different from the actual parameters. In addition, the accuracy and response speed of the components and parts of the experimental systems cannot compare with those of the simulation systems. Therefore the steady state error of the experimental results is larger than that of the simulation results. However, the shape and trend of the experimental curves, especially the influence of the accumulator, are consistent with the simulation results. Both the simulation results and the experimental results show that the system with accumulator can achieve the goal with a faster speed than the system without accumulator, while the steady state error is acceptable for the hydraulic impulse testing equipment.

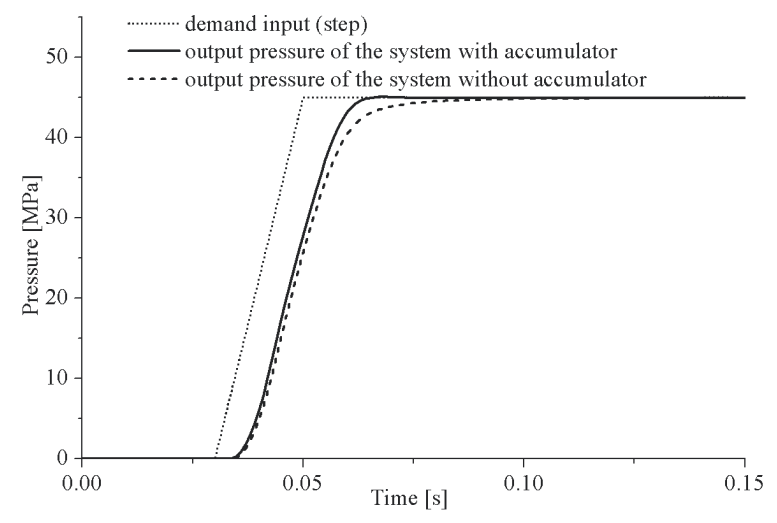

Fig. 12. Simulation results of step-input

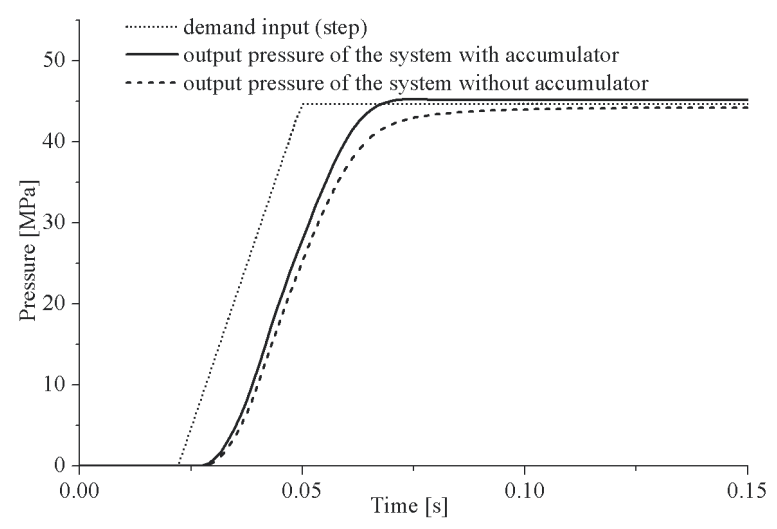

Fig. 13. Experiment results of step-input

Table 5. Key data of the simulation results of step-input

\begin{tabular}{lccc}
\hline & $\begin{array}{c}\text { Demand } \\
\text { input }\end{array}$ & $\begin{array}{c}\text { System without } \\
\text { accumulator }\end{array}$ & $\begin{array}{c}\text { System with } \\
\text { accumulator }\end{array}$ \\
\hline Rise time [ms] & 18 & 51 & 35 \\
\hline Final value [MPa] & 45 & 44.9 & 44.96 \\
\hline Steady state error [\%] & - & 0.2 & 0.09 \\
\hline
\end{tabular}

Table 6. Key data of the experiment results of step-input

\begin{tabular}{lccc}
\hline & $\begin{array}{c}\text { Demand } \\
\text { input }\end{array}$ & $\begin{array}{c}\text { System without } \\
\text { accumulator }\end{array}$ & $\begin{array}{c}\text { System with } \\
\text { accumulator }\end{array}$ \\
\hline Rise time [ms] & 24 & 60 & 42 \\
\hline Final value [MPa] & 44.7 & 44.3 & 45.14 \\
\hline Steady state error [\%] & - & 0.9 & 1 \\
\hline
\end{tabular}




\subsection{Square-Wave-Input Response}

For the hydraulic impulse testing equipment, the most commonly adopted pressure wave forms are the square-wave and the peak-wave. The squarewave-input response of the system with and without accumulator is studied. Both simulations and experiments were carried out and the results are shown in Figs. 14 and 15. As can be seen from the results, both systems can achieve the goal with a minor steady state error. However, the system with accumulator can achieve the goal with a faster speed than the system without accumulator.

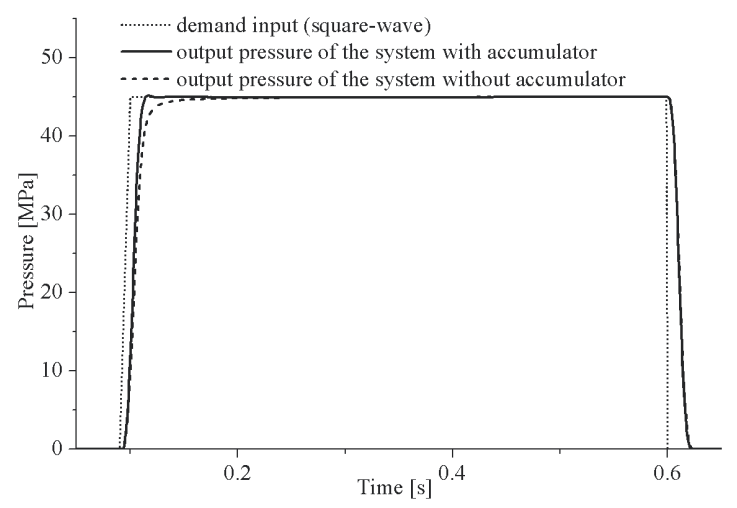

Fig. 14. Simulation results of square-wave-input

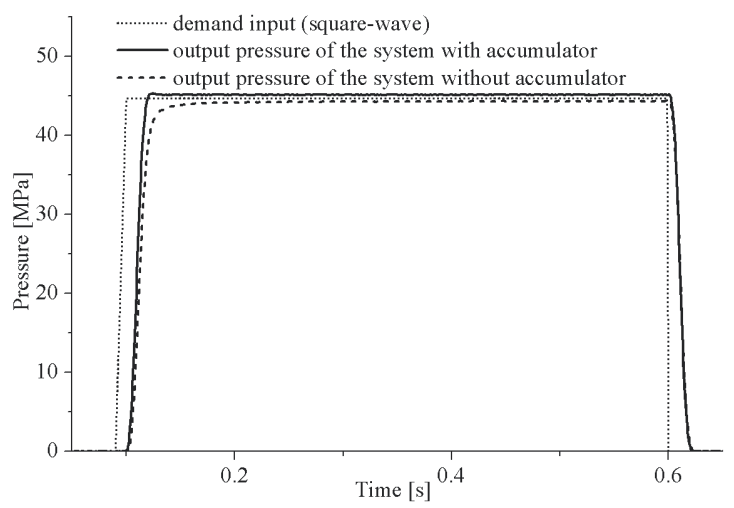

Fig. 15. Experiment results of square-wave-input

As with the step-input response, the response time lag and steady state error of the experimental results are larger than that of the simulation results, the reason for this is that the damping forces of the seals and the piston in the simulation model are neglected, and some parameters such as the bulk modulus of the hydraulic oil may be slightly different from the actual parameters. However, the shape and trend of the experiment curves, especially the influence of the accumulator, are consistent with the simulation results. Both the simulation results and the experiment results show that the system with accumulator can achieve the goal with a faster speed than the system without accumulator.

\subsection{Peak-Wave-Input Response}

The peak-wave-input response of the hydraulic impulse testing system with and without accumulator is studied. Both simulations and experiments were carried out and the results are shown in Figs. 16 and 17. It can be seen from the results that the pressure rise rate of the hydraulic impulse testing system with accumulator is larger than that of the system without accumulator. Since the pressure rise rate of the peakwave is relatively large, the system with accumulator can achieve the goal better.

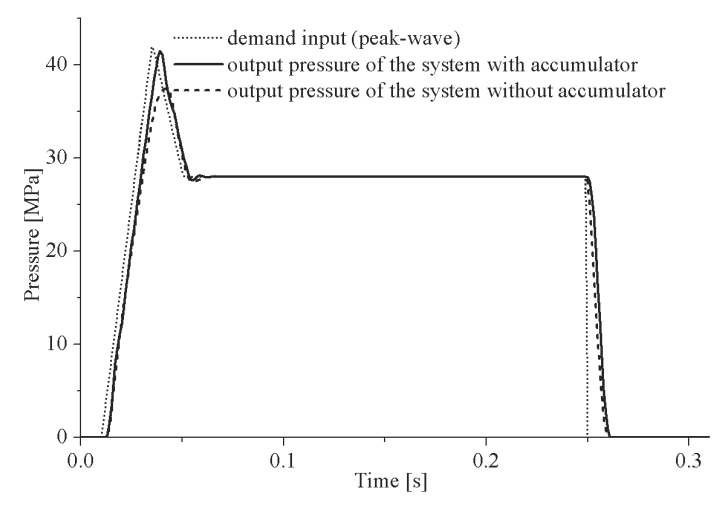

Fig. 16. Simulation results of peak-wave-input

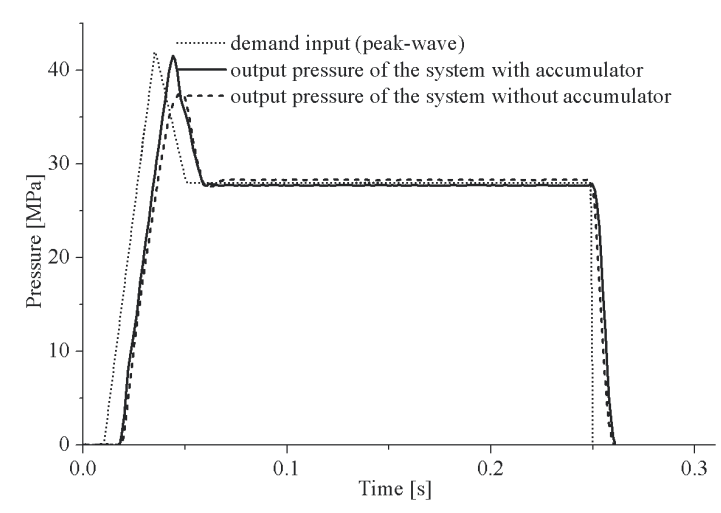

Fig. 17. Experiment results of peak-wave-input

As with the step-input response and squarewave-input response, the response time lag of the experimental results is larger than that of the simulation results, the reason for this is that the damping forces of the seals and the piston in the simulation model are neglected, and some parameters such as the bulk modulus of the hydraulic oil may 
be slightly different from the actual parameters. However, the shape and trend of the experiment curves, especially the influence of the accumulator, are consistent with the simulation results. Both the simulation results and the experiment results show that the system with accumulator can achieve the goal better, with a larger pressure rise rate than the system without accumulator.

\section{CONCLUSIONS}

An energy regeneration system for hydraulic impulse testing equipment with accumulator is proposed, which serves as a form of novel energy-saving hydraulic impulse testing equipment. Mathematical analysis and simulations show that the hydraulic impulse testing system with accumulator can reduce energy consumption by $15 \%$ over that of a system without an accumulator in the cycle, while the energy efficiency of the hydraulic impulse testing system is increased from 62.82 to $75.71 \%$ by the adoption of an accumulator. Both simulation and experimental results show that the control performance of the hydraulic impulse testing equipment with accumulator is better than that of the equipment without accumulator: more specifically, a faster response speed and a larger pressure rise rate are achieved. In addition, the most commonly adopted pressure wave forms for hydraulic impulse testing, including square-wave and peakwave, can be obtained by the energy regeneration system with accumulator.

\section{ACKNOWLEDGEMENTS}

The authors would like to thank the sponsor of the Science Fund for Creative Research Groups of the National Natural Science Foundation of China (No: 51221004).

\section{REFERENCES}

[1] Wang, F., Gu, L. Chen, Y. (2013). A Hydraulic Pressure-Boost System Based on High-Speed. IEEE/ASME Transactions on Mechatronics, vol. 18, no. 2, p. 733-743, D0l:10.1109/ TMECH.2011.2182654.

[2] Lin, T., Wang, Q. (2012). Hydraulic accumulator-motorgenerator energy regeneration system for a hybrid hydraulic excavator. Chinese Journal of Mechanical Engineering, vol. 25, no. 6, p. 1121-1129, D0l:10.3901/CJME.2012.06.1121.

[3] Ho, T.H., Ahn, K.K. (2010). Modeling and simulation of hydrostatic transmission system with energy regeneration using hydraulic accumulator. Journal of Mechanical Science and Technology, vol. 24, no. 5, p. 1163-1175, Dol:10.1007/ s12206-010-0313-8.
[4] Do, H.T., Ahn, K.K. (2013). Velocity control of a secondary controlled closed-loop hydrostatic transmission system using an adaptive fuzzy sliding mode controller. Journal of Mechanical Science and Technology, vol. 27, no. 3, p. 875884, D0I:10.1007/s12206-012-1237-2.

[5] Wang, C., Jiao, Z., Wu, S., Shang, Y. (2014). Nonlinear adaptive torque control of electro-hydraulic load system with external active motion disturbance. Mechatronics, vol. 24, no. 1, p.3240, D0l:10.1016/j.mechatronics.2013.11.005.

[6] Minav, T., Hänninen, H., Sinkkonen, A., Laurila, L., Pyrhönen, J. (2014). Electric or hydraulic energy recovery systems in a reach truck- a comparison. Strojniški vestnik - Journal of Mechanical Engineering, vol. 60, no. 4, p. 232-240, D0I:10.5545/sv-jme.2013.1581.

[7] Andersen, T.O., Hansen, M.R., Pedersen, H.C. (2005). Regeneration of potential energy in hydraulic forklift trucks. The $6^{\text {th }}$ International Conference on Fluid Power Transmission and Control, Hangzhou, p. 380-384.

[8] He, W., Zhang, S., Ge, S.S. (2014). Adaptive control of a flexible crane system with the boundary output constraint. IEEE Transactions on Industrial Electronics, vol. 61, no. 8, p. 41264133, DOI:10.1109/TIE.2013.2288200.

[9] Bing, X., Jian, Y., Yang, H.Y. (2005). Comparison of energy-saving on the speed control of the VVVF hydraulic elevator with and without the pressure accumulator. Mechatronics, vol. 15, no. 10, p. 1159-1174, D0l:10.1016/j. mechatronics.2005.06.009.

[10] Lin, T.L., Wang, Q.F., Hu, B.Z., Gong, W. (2010). Research on the energy regeneration systems for hybrid hydraulic excavators. Automation in Construction, vol. 19, no.8, p. 10161026, D0I:10.1016/j.autcon.2010.08.002.

[11] Evans, C.W. (1980). Testing requirements for hydraulic hose. Polymer Testing, vol. 1, no. 1, p. 39-49, Dol:10.1016/01429418(80)90025-2.

[12] BS EN ISO 6802:2008. Rubber and Plastics Hoses and Hose Assemblies with Wire Reinforcements - Hydraulic Impulse Test with Flexing. International Organization for Standardization, Geneva.

[13] ISO 1436:2009. Rubber Hoses and Hose Assemblies - WireBraid-Reinforced Hydraulic Types for Oil-Based or WaterBased Fluids - Specification. International Organization for Standardization, Geneva.

[14] ISO 6605:2002. Hydraulic Fluid Power - Hoses and Hose Assemblies - Test Methods. International Organization for Standardization, Geneva.

[15] ISO 6772:1988. Aerospace - Fluid Systems - Impulse Testing of Hydraulic Hose, Tubing and Fitting Assemblies. International Organization for Standardization, Geneva.

[16] SAE AIR1228 (2007). Standard Impulse Machine Equipment and Operation. Society of Automotive Engineers, Warrendale.

[17] Kim, H.E., Lee, G.C. Kim, J.H. (2010). System design and performance test of hydraulic intensifier. Transactions of the Korean Society of Mechanical Engineers, vol. 34, no. 7, p. 947-952, D0l:10.3795/KSME-A.2010.34.7.947. (in Korean)

[18] Song, K., Zhao, S., Liao, J., Dou, Y., Zhao, X. (2011). Research on key technology of hydraulic impulse testing equipment. Journal of Aerospace Engineering, vol. 24, no. 4, p. 409-414, DOI:10.1061/(ASCE)AS.1943-5525.0000086. 